Donnie Jan L. Segocio, MD

Christine D. Dayanghirang, MD

Joseph E. Cachuela, MD

Department of Otorhinolaryngology Head and Neck Surgery

Southern Philippines Medical Center
Correspondence: Dr. Donnie Jan L. Segocio Department of Otorhinolaryngology Head and Neck Surgery

Southern Philippines Medical Center

Davao City 8000

Philippines

Phone: (+63) 922896 9978; (+63) 9178692111

Email: ronaldonnie@gmail.com

The authors declared that this represents original material that is not being considered for publication or has not been published or accepted for publication elsewhere in full or in part, in print or electronic media; that the requirements for authorship have been met by all the authors, and that each author believes that the manuscript represents honest work.

Disclosures: The authors signed a disclosure that there are no financial or other (including personal) relationships, intellectual passion, political or religious beliefs, and institutional affiliations that might lead to a conflict of interest.

Presented at the Philippine Society of Otolaryngology Head and Neck Surgery Interesting Case Contest. June 2, 2015, Menarini Building, BGC, Taguig City.

Presented at the Southern Philippines Medical Center Annual Residents'Interesting Case Contest. August 2013. JICA building, Southern Philippines Medical Center, Davao City.

\section{A 15-Year Occult Foreign Body in the Subglottic Area of a 50-Year-Old Woman}

\begin{abstract}
Objective: To present a case of subglottic foreign body (FB) impaction in a 50-year-old woman diagnosed with bronchial asthma for 15 years.
\end{abstract}

\section{Methods:}

\author{
Design: Case Report \\ Setting: Tertiary Public Hospital \\ Patient: One
}

Results: A 50-year-old woman with recurrent cough and dyspnea for 15 years that had been managed as bronchial asthma developed stridor and halitosis in the last 5 years. Flexible laryngoscopy revealed a subglottic mass and CT scan confirmed a suspicious foreign body in the lumen of the subglottis. Signs and symptoms resolved after peroral endoscopic removal of the foreign body from the larynx. Histopathology of the extracted material from the airway confirmed it to be "bone tissue."

Conclusion: Foreign body aspiration can occur in adults without predisposing factors. Its diagnosis can be challenging as it can mimic respiratory disorders such as bronchial asthma. Endoscopy and computed tomography are valuable for correct diagnosis and management. An incorrect initial diagnosis should be considered in the light of unresolved symptoms and prompt referral to an appropriate specialist may prevent undue suffering and dangerous complications.

\section{Keywords: foreign body aspiration, occult airway foreign body}

Foreign body aspiration commonly occurs in patients with neurological impairment, alcohol intoxication, and head trauma, more commonly in children and elderly. ${ }^{1}$ Foreign body aspiration in adults without these risk factors is rare, and long-standing persistence for 15 years is even rarer. We present a case of subglottic foreign body (FB) impaction in a 50-year-old woman diagnosed with bronchial asthma for 15 years.

\section{CASE REPORT}

A 50-year-old local government employee consulted because of cough, recurrent dyspnea, biphasic stridor and halitosis. She had complained of recurrent cough and dyspnea for 15 years. Her family physician diagnosed bronchial asthma and treated her with inhaled bronchodilators, mucolytics, antibiotics and corticosteroids. Several other consults were made because symptoms only partially resolved and would recur despite multiple interventions for asthma and respiratory 


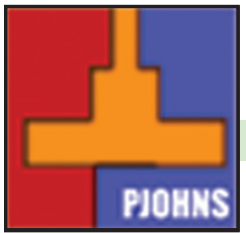

tract infection. There were also multiple hospital admissions for bouts of cough and dyspnea treated with inhaled corticosteroids, bronchodilators and occasional antibiotics. Several peak flow tests revealed a low normal result. Repeated chest radiographs were unremarkable. She developed halitosis and episodic biphasic stridor in the last 5 of those 15 years eventually prompting otolaryngologic consult.

On examination, the patient had supraclavicular retractions, a respiratory rate of 20 per minute and oxygen saturation of $98-100 \%$. There was episodic biphasic stridor especially on deep breathing with inspiratory and expiratory wheezes on auscultation. Halitosis was evident. Flexible laryngoscopy showed a suspicious mass in the subglottic area causing about 30\% airway obstruction. The vocal cords were fully mobile but edematous. (Figure 1)

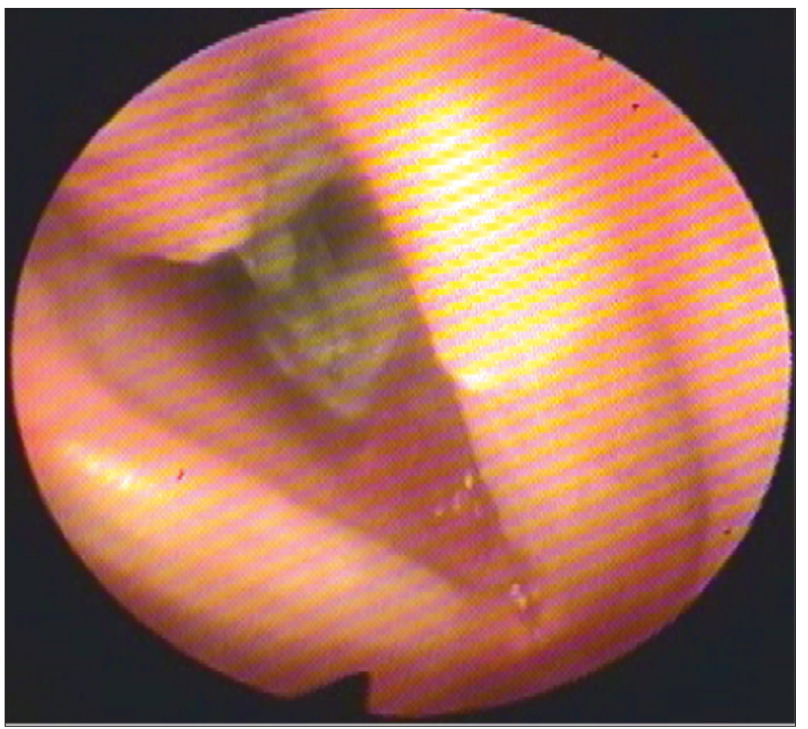

Figure 1. Flexible laryngoscopic view of subglottic foreign body with granulation tissue and airway obstruction of about $30 \%$.
A Computed Tomography (CT) scan of the neck revealed a Y-shaped radiopaque foreign body in the lumen of the subglottic region oriented in a sagittal plane with swelling of the 'mucosa and corresponding narrowing of the airway. There was also obliteration of the paralaryngeal fat indicating mild edema of the larynx. The airway above the larynx and below the foreign body was normal. (Figure 2)

Review of history revealed a choking incident while eating 15 years ago, followed by paroxysms of cough then breathiness of the voice. A general physician consulted advised the patient to rest. Breathiness persisted for about a year associated with recurrent cough and dyspnea. After one year of breathiness and hoarseness, vocal production returned to normal, but she had repeated consults with and admissions under different physicians due to recurrent cough and dyspneic episodes. For 15 years, she had been managed without relief as a case of bronchial

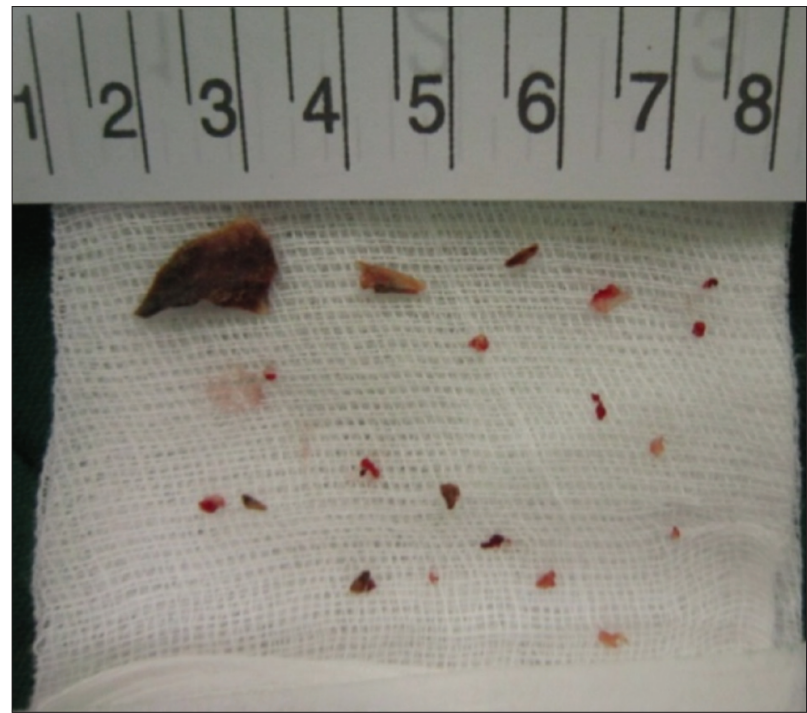

Figure 3. Extracted foreign body measuring $1.5 \mathrm{~cm} \times 0.3 \mathrm{~cm} \times 0.7 \mathrm{~cm}$ with granulation tissue.

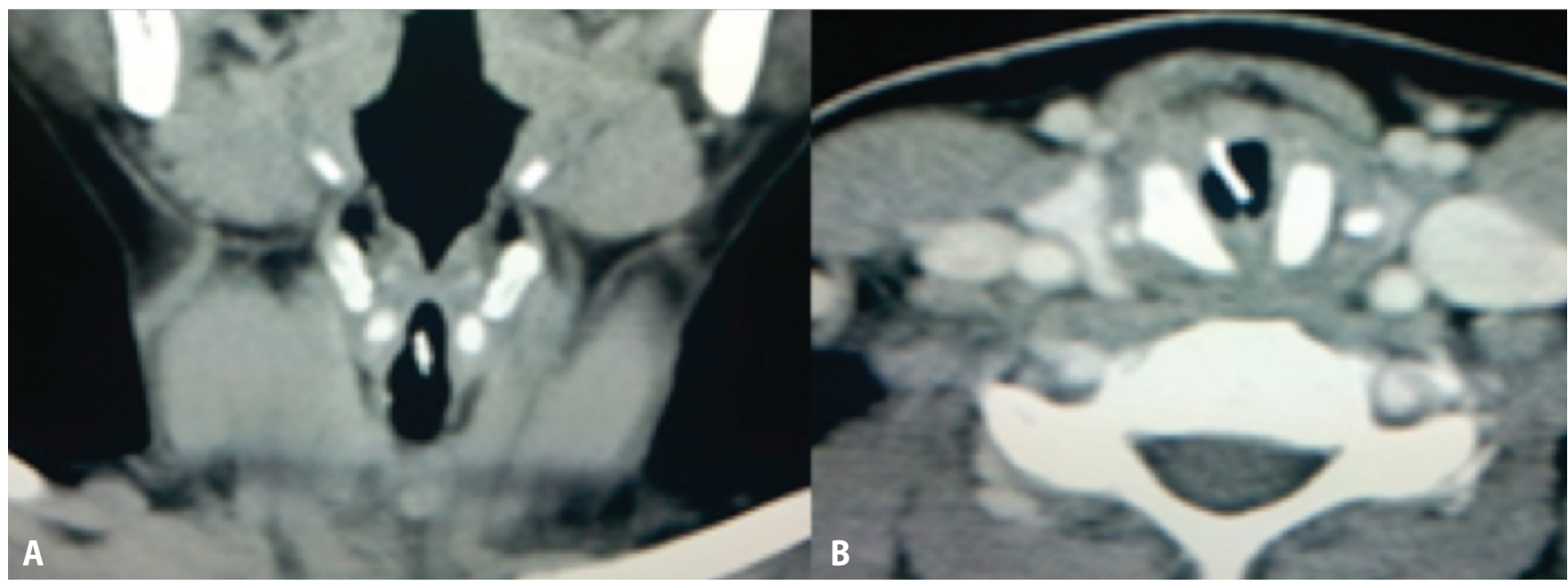

Figure 2. CT Scan of the Neck A. Coronal view B. Axial view showing sagitally-oriented radiopaque foreign body in the lumen of the subglottic region. 


\section{CASE REPORTS}

asthma. She had even been advised to quit work due to the frequency and progressive intensity of exacerbations.

With a diagnosis of laryngeal foreign body impaction, a tracheostomy was performed to secure the airway and ensure adequate ventilation during foreign body extraction. Direct laryngoscopy and removal of foreign body and granulation tissue yielded a bony hard, $1.5 \times 0.3 \times 0.7$ $\mathrm{cm}$ object surrounded by granulation tissue causing $30 \%$ obstruction of the airway immediately below the vocal cords. (Figure 3 ) The subglottic airway diameter at the level of the foreign body was collectively $7 \mathrm{~mm}$.

The procedure was well tolerated. She was decannulated on the $3^{\text {rd }}$ postoperative day and discharged improved on the $4^{\text {th }}$ postoperative day. Dyspnea, retractions, halitosis and biphasic stridor resolved completely one week following surgery. The final histopathologic report revealed "bone tissue." (Figure 4)

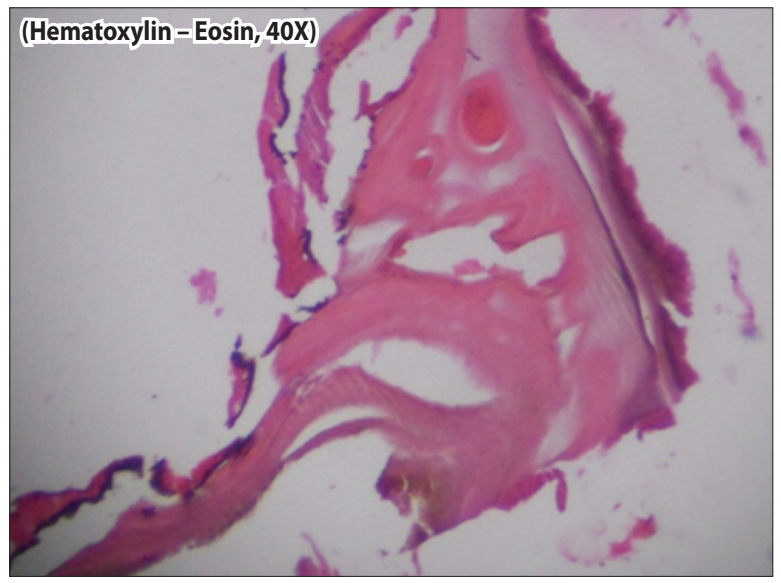

Figure 4. Histolopathologic specimen, Hematoxylin-Eosin, high power magnification (40x) revealed foreign body consistent with bone tissue.

\section{DISCUSSION}

Foreign bodies in the aero-digestive tract are frequently encountered in otolaryngology. They are most common among toddlers (peaking at 3 years of age) and rare in adults. ${ }^{2}$ This is because airway-protective reflexes are not as effective in children. Adults with predisposing factors such as advancing age, history of dental extraction and altered level of consciousness from sedation, trauma, intoxication or other neurologic problems are prone to foreign body aspiration. ${ }^{3-5}$ Adults with no known risk factors like this patient can aspirate a foreign body if there is interference in the normal reflex action such as when laughing, playing or other circumstances where there is sudden inhalation while eating. ${ }^{6}$

The most frequently reported foreign bodies encountered in adults are dentures, meat bolus and bones that usually lodge in the bronchus (80\%) but rarely in the subglottic area. ${ }^{7,8}$

There are three distinct clinical phases that occur after a foreign body is aspirated and these are associated with various clinical manifestations. ${ }^{9}$ The first phase occurs immediately following the incident. The main symptoms are coughing (72\%), wheezing (53\%), and dyspnea (25\%). ${ }^{2}$ These were manifested by the patient for 15 years. The occurrence of death is very high during this phase of aspiration especially in children. ${ }^{7}$ However, irregular foreign bodies tend to orient in a sagittal plane, as manifested by this patient, and may produce only partial obstruction. ${ }^{10}$ This affords adequate airflow allowing the foreign body to remain undetected for a long period of time. ${ }^{10}$

The second phase is the asymptomatic period that can last from minutes to months or even years following the incident ${ }^{11}$ The duration of this period depends on the location of the foreign body, the degree of airway obstruction, and the type of material aspirated ${ }^{11}$ This phase is the most treacherous and accounts for large percentage of misdiagnosed and overlooked foreign bodies ${ }^{9}$ as presented by our patient.

The third clinical phase is the renewed symptomatic period due to the presence of complications secondary to the aspirated foreign body. ${ }^{2,9}$ Airway inflammation or infection from the foreign body will cause symptoms of cough, wheezing, halitosis, fever, sputum production, and occasionally, hemoptysis. ${ }^{3,12}$

Obstructive lung disease like bronchial asthma was strongly considered since the patient had recurrent cough and dyspnea temporarily relieved by bronchodilators and steroids. Furthermore, she had a peak flow below normal and repeatedly unremarkable chest radiographs. Although she had not been diagnosed with asthma in childhood, she could have had adult-onset asthma, because it is less well controlled and more likely to be non-atopic. ${ }^{13}$ Risk factors include obesity, allergies and exposure to asthma-triggers like tobacco smoke and dust. ${ }^{13,14}$ which were not significantly present in the patient. Asthma can be clinically diagnosed when presented with wheezing associated with shortness of breath, usually relieved with bronchodilators and corticosteroids, as partly manifested by the patient. However, to appropriately diagnose asthma, we need further tests like spirometry and bronchial challenge testing. ${ }^{14,15}$

The current medical practice of treating asthmatics with antibiotics and corticosteroids may obscure signs and symptoms that would normally be expected with a retained foreign body. ${ }^{9}$ Clearing of symptoms with these agents cannot always be assumed to be diagnostic of a specific disease process. The fact that a wheeze disappears or a pneumonic process temporarily clears may merely mean that the reaction to a foreign body has been temporarily controlled. ${ }^{9}$ Recurrence after tapering of therapy should heighten a physician's suspicion of an aspirated foreign body. ${ }^{9}$ With the patient's clinical manifestations and poor response to medications, a diagnosis other than asthma should have been considered.

Although rare with prolonged use of corticosteroids advancing age 


\section{CASE REPORTS}

and female sex, the patient may be predisposed to develop tracheal stenosis. This can also present with gradual onset of dyspnea associated with wheezing and a low normal peak flow values but is unresponsive to steroids and bronchodilators. This can be further investigated with spirometry to determine the characteristic flow volume loops that would differentiate asthma from upper airway-narrowing pathologies like tracheal stenosis, laryngeal neoplasms and laryngeal foreign body impaction. With the characteristic flattening of the flow-volume loop in spirometry, ${ }^{16}$ asthma can be ruled out and investigation for obstruction via direct visualization of the airways using fiberoptic laryngobronchoscopy should be performed.

Laryngeal malignancy and inflammatory and granulomatous diseases of the larynx may also be considered in a patient with recurrent cough and dyspnea with biphasic stridor, halitosis and an endoscopic finding of suspicious mass in the subglottic area. However, the history and physical examination findings and CT scan demonstrating a bony opacity in the upper airway ruled these out.

The diagnosis of FB aspiration can be challenging despite the availability of advanced imaging techniques. Foreign body aspiration in adults tends to be long-standing with a lack of history of aspiration. ${ }^{17}$ Occult foreign bodies can remain undetected for a long time leading to a delay in the diagnosis especially in cases where the clinical picture mimics a more common condition such as respiratory tract infection or asthma. ${ }^{5}$

A chest radiograph is the initial imaging modality. In this case, chest radiographs failed to demonstrate the foreign body in the airway as it was not significant enough to cause radiologic lung changes. Chest X-Rays have poor sensitivity for aspirated foreign bodies, which are not all visible on radiographs. ${ }^{18}$ The most common findings are pulmonary infiltrations, atelectasis, hyperinflation, bronchiectasis, or even normal appearance. The chance of having a normal chest $\mathrm{x}$ ray was as high as $24 \%$. ${ }^{1}$ Therefore, the diagnosis relies on a high level of clinical suspicion not on imaging studies. ${ }^{19}$

Extraction is the definitive treatment of foreign body aspiration. Until the late 1800, airway foreign body was removed via bronchotomy. With the advent of technology, rigid bronchoscopes and flexible bronchoscopes are now widely used for airway foreign body extraction. In cases of endoscopic failure, thoracotomy is an option. ${ }^{20}$

During surgery, the airway must be secured and any soft tissue swelling that could lead to airway obstruction must be taken into account. ${ }^{19}$ In this case, the patient was not in respiratory distress with good oxygen saturation thus no urgent intervention was initiated. An elective tracheostomy was performed prior to the operative removal of the foreign body.

Indeed, the caveat, "not all that wheezes is asthma" is truly demonstrated in this patient. As seen in our case, foreign body aspiration can occur in adults without predisposing factors. Failure to recall an incident of choking does not rule out its diagnosis, which can be challenging as it can mimic respiratory disorders such as bronchial asthma. Endoscopy and computed tomography are valuable for correct diagnosis and management. An incorrect initial diagnosis should be considered in the light of unresolved symptoms and prompt referral to an appropriate specialist may prevent undue suffering and dangerous complications.

\section{ACKNOWLEDGEMENTS}

The authors would like to thank Dr. Veronica Magnaye and Dr. Hannah Grace B. Segocio who provided input, support, encouragement and helped critique and appraise this paper to, residents of the department of ORL-HNS SPMC who assisted in performing the surgical technique.

\section{REFERENCES}

1. Mise K, Jurcev Savicevic A, Pavlov N, Jankovic S. Removal of tracheobronchial foreign bodies in adults using flexible bronchoscopy: experience 1995-2006. Surg Endosc 2009 Jun;23(6):13601364. DOI: 10.1007/s00464-008-0181-9. PubMed PMID: 18923871.

2. Enzan K, Mitsuhata H, Sato W, Suzuki M. [Statistical analysis of tracheobronchial foreign bodies]. Masui. 1991 Sep: 40(9): 1417-1422. PMID: 1942519. PubMed PMID: 1942519.

3. Ben-Dov I, Aelony Y. Foreign body aspiration in the adult: an occult cause of chronic pulmonary symptoms. Postgrad Med J. 1989 May; 65 (763): 299-301. PubMed PMID: 2692009 PubMed Central PMCID: PMC2429316.

4. Khan NS, Khan AR, Din S, Sattar F. Management of subglottic foreign body, a therapeutic challenge. JPMI Journal of Postgraduate Medical Institute 2004; 18(4):658-662.

5. Rolfe LM, Rayner CF. A wheezy man with a bony abnormality. Postgrad Med J. 1999 Aug; 75(886): 503-505. DOI: 10.1136/pgmj.75.886.503. PubMed PMID: 10646039 PubMed Central PMCID: PMC1741311.

6. Musani MA, Khambaty Y, Jawed I, Khan FA, Ashrafi SK. An unusual foreign body in trachea. $J$ Ayub Med Coll Abbottabad. 2010 Jan-Mar; 22(1):178-179. PubMed PMID: 21409938

7. Baharloo F, Veyckemans F, Francis C, Biettlot MP, Rodenstein DO. Tracheobronchial foreign bodies: presentation and management in children and adults. Chest. 1999 May; 115(5):1357-62 PubMed PMID: 10334153.

8. Umana AN, Offiong ME, Ewa AU, Francis P, Adekanye A, Mgbe RB, et al. Foreign body (disk battery) in the oesophagus mimicking respiratory problem in a 13 months old baby-delayed diagnosis. Journal of Medicine and Medical Science. 2011 Mar; 2(3):714-717.

9. Wei JL, Holinger LD. Management of foreign bodies of airway. In: Shields TW, LoCicero III J, Reed $\mathrm{CE}$, Feins RH, editors. General thoracic surgery. Philadephia: Lippincott Williams and Wilkins; 2009. p. 927-930.

10. Philip A, Rajan Sundaresan V, George P, Dash S, Thomas R, Job A, et al. A reclusive foreign body in the airway: a case report and a literature review. Case Rep Otolaryngol. 2013; 2013 347325, 4 pages. DOI: 10.1155/2013/347325 PubMed PMID: 24312739 PubMed Central PMCID: PMC3838836.

11. Fong EW. Foreign Body Aspiration. In: Yamamoto LG, Inaba AS, Okamoto JK, Patrinos ME, Yamashiroya VK, editors. Case based pediatrics for medical students and residents. [monograph on the internet] Honolulu: Department of Pediatrics, University of Hawaii John A Burns School of Medicine; c2004. [cited 2013 May 6] Available from: http://www.hawaii.edu/medicine/ pediatrics/pedtext/ p. 311-314

12. Sardana P, Bais AS, Singh VP, Arora M. Unusual foreign bodies of the aerodigestive tract. Indian Otolaryngol Head Neck Surg. 2002 Apr: 54(2):123-126. DOl: 10.1007/BF02968730 PubMed PMID: 23119872 PubMed Central PMCID: PMC3450538.

13. Burdon J. Adult-onset asthma. Aust Fam Physician 2015 Aug; 44(8): 554-57. PubMed PMID: 26510141.

14. Dundas I, Mckenzie S. Spirometry in the diagnosis of asthma in children. Curr Opin Pulm Med. 2006 Jan; 12(1):28-33. PubMed PMID: 16357576

15. Sumino K, Sugar EA, Irvin CG, Kaminsky DA, Shade D, Wei CY, et al. Methacholine challenge test: diagnostic characteristics in asthmatic patients receiving controller medications. J Allergy Clin Immunol. 2012 Jul; 130(1):69-75. DOI: 10.1016/j.jaci.2012.02.025 PubMed PMID: 22465214.

16. Apostolova M, Zeidan B. A case of idiopathic tracheal stenosis. Respir Med Case Rep. 2013 Jul 24; 10:15-18. DOI: 10.1016/j.rmcr.2013.05.002 PubMed PMID: 26029504 PubMed Central PMCID: PMC3920420.

17. Singh A, Kaur M. Recurrent Pneumonitis due to Tracheobronchial Foreign Body in an Adult JIACM Journal, Indian Academy of Clinical Medicine. 2007 Jul-Sep; 8(3):242-244.

18. Zohny AG. Bronchoscopy for foreign body removal: Practical guidelines. EJENTAS Egyptian Journal of ear, nose, throat and Allied Sciences. 2009 Dec; 10:31-36.

19. Wu TH, Cheng YL, Tzao, C, Chang H, Hsieh CM, Lee SC. Longstanding tracheobronchial foreign body in an adult. Respir Care. 2012 May; 57(5):808-810. DOI: 10.4187/respcare.01445 PubMed PMID: 22152102.

20. Murray AD, Talavera F, Meyers AD, Kelly DJ. Foreign Bodies of airway. Medscape. 2015 May: (about 6 p.). [cited 2016 Oct 6]. Available from: http://emedicine.medscape.com/article/872498overview\#a5. 